\title{
Effect of Soaking Time on the Phase Transformation of Porous Biphasic $\beta$-Tricalcium Phosphate/Carbonate Apatite Scaffold
}

\author{
Nur Nadhirah Muhaime, ${ }^{1}$ Ira Artillia ${ }^{2}$ and Nurazreena Ahmad ${ }^{1 *}$ \\ ${ }^{1}$ School of Materials and Mineral Resources Engineering, Universiti Sains Malaysia, \\ Engineering Campus, 14300 Nibong Tebal, Pulau Pinang, Malaysia \\ ${ }^{2}$ Department of Dental Materials Science and Technology, Programme Study of \\ Dentistry, Faculty of Medicine, Universitas Jenderal Achmad Yani, Cimahi, Indonesia \\ "Corresponding author: nurazreena@usm.my
}

Published online: 25 December 2019

To cite this article: Muhaime, N. N., Artillia, I. \& Ahmad, N. (2019). Effect of soaking time on the phase transformation of porous biphasic $\beta$-tricalcium phosphate/carbonate apatite scaffold. J. Phys. Sci., 30(Supp. 2), 65-75, https://doi.org/10.21315/jps2019.30.s2.6

To link to this article: https://doi.org/10.21315/jps2019.30.s2.6

\begin{abstract}
In recent years, focuse has moved to multiphase calcium orthophosphate scaffolds to balance the more stable calcium orthophosphate phase with another more soluble phase. This will enable the researchers to tailor the major biomedical properties to suit its intended application. In this study, beta tricalcium phosphate ( $\beta$-TCP)/carbonate apatite $\left(\mathrm{CO}_{3} \mathrm{Ap}\right)$ scaffolds were fabricated via freeze drying method. The effect of soaking time ( $2 \mathrm{~h}, 4 \mathrm{~h}$ and $6 \mathrm{~h}$ ) on the phase transformation of $\beta$ to alpha $(\alpha)$ phase was investigated. The scaffolds were sintered at $1300^{\circ} \mathrm{C}$ for respective soaking time and quenched in air to obtain biphasic $\beta$-TCP/ $\alpha$-TCP scaffolds. To obtain biphasic $\beta-T C P / C O_{3}$ Ap scaffold, the obtained scaffolds were then subjected to hydrothermal treatment in $1 \mathrm{M}$ of sodium bicarbonate at $200^{\circ} \mathrm{C}$ for 5 days for phase transformation of $\alpha$-TCP phase into $\mathrm{CO}_{3} \mathrm{Ap}$ phase via dissolution-precipitation process. X-ray diffraction (XRD) analysis before hydrothermal treatment confirms the existence of biphasic $\beta$ and $\alpha$ phase at all soaking time. The percentage of $\alpha$ phase increases as soaking time increases. Fourier transform infrared (FTIR) analysis confirms the present of carbonate ions substitution into the scaffold after hydrothermal treatment. Therefore, it is concluded that as soaking time increases, the unstable phase of $\alpha-T C P$ increases in the biphasic $\beta-T C P / \alpha-T C P$ scaffolds. Thus, the phase transformation from $\alpha$-TCP phase to $\mathrm{CO}_{3} \mathrm{Ap}$ phase increases as soaking time increases.
\end{abstract}

Keywords: Biphasic $\beta$-tricalcium phosphate, carbonate apatite, scaffold, dissolutionprecipitation reaction, hydrothermal treatment 


\section{INTRODUCTION}

In recent years, calcium phosphate $(\mathrm{CaP})$ has been widely used as bone substitute due to their chemical composition that are similar to bone mineral. Common $\mathrm{CaP}$ used are hydroxyapatite (HAp), $\beta$-tricalcium phosphate $(\beta-\mathrm{TCP})$ and their combination as biphasic calcium phosphate (BCP). HAp has great biocompatibility and a favourable osteogenic potential since it is more similar to mineral part of the bone. Despite these characteristics, HAp has poor biodegradability where it may remain integrated into the regenerated bone tissue once implemented into the body. ${ }^{1}$ Contrary to HAp, $\beta$-TCP degrades faster without osteoclastic resorption indicating that the rate of $\beta$-TCP resorption does not correspond to that of bone formation. ${ }^{2}$ The imbalance between resorption and osteogenesis results in the deterioration of the bone quality. ${ }^{3}$ This is because $\beta$-TCP dissolves completely before new bone tissues are formed. ${ }^{4}$ To overcome this problem, carbonate apatite $\left(\mathrm{CO}_{3} \mathrm{Ap}\right)$ is introduced as compared to HAp, and it was reported that $\mathrm{CO}_{3} \mathrm{Ap}$ has higher degradability rate thus can be replaced by the newly formed tissues. ${ }^{5}$ Importantly, $\mathrm{CO}_{3} \mathrm{Ap}$ is resorbed only by osteoclastic resorption, therefore its resorption rate closely matches the natural bone. ${ }^{6}$

However, $\mathrm{CO}_{3} \mathrm{Ap}$ cannot be sintered like $\mathrm{HAp}$ due to the decomposition of carbonate at high temperature. Therefore, $\mathrm{CO}_{3} \mathrm{Ap}$ should be fabricated using phase transformation of unstable precursors based on dissolution-precipitation reactions. ${ }^{7}$ Alpha tricalcium phosphate $(\alpha-\mathrm{TCP})$ has been reported to transform to $\mathrm{CO}_{3} \mathrm{Ap}$ when subjected to hydrothermal treatment in ammonium carbonate $\left(\left(\mathrm{NH}_{4}\right)_{2} \mathrm{CO}_{3}\right)$ solution at $200^{\circ} \mathrm{C}$ for $24 \mathrm{~h} .{ }^{8}$ In this research, to synthesise biphasic $\beta-\mathrm{TCP} / \mathrm{CO}_{3} \mathrm{Ap}$ scaffold, initially the present of $\alpha$-TCP phase must exist in the $\beta$-TCP scaffold prior to dissolution-precipitation reactions in hydrothermal method. Therefore, in this study, $\beta$-TCP scaffolds were prepared via freeze drying method and the effect of soaking time during sintering on the formation of $\alpha$-TCP phase were investigated. Biphasic porous $\alpha-\mathrm{TCP} / \beta$-TCP were then subjected to dissolutionprecipitation reaction via hydrothermal technique.

\section{EXPERIMENTAL}

\subsection{Materials}

The raw materials used in the fabrication of the scaffold were beta-tricalcium phosphate ( $\beta$-TCP, Sigma Aldrich), polyvinyl alcohol (PVA, Sigma Aldrich) with molecular weight average of 14000 and glutaraldehyde (GA, Merck, Germany). While the material used for the dissolution-precipitation reaction was sodium bicarbonate $\left(\mathrm{NaHCO}_{3}, \mathrm{BDH}\right.$ Chemicals). 


\subsection{Preparation of $\beta$-TCP Scaffold}

Freeze dryer (LyoQuest-55, TELSTAR, Switzerland) was used to freeze $\beta$-TCP slurries in polyvinyl chloride (PVC) pipe. The slurries were produced by mixing gelatine $(1 \mathrm{wt} \%, 3 \mathrm{wt} \%$ and $5 \mathrm{wt} \%)$ with $65 \mathrm{wt} \%$ of distilled water at $60^{\circ} \mathrm{C}$ while stirred with magnetic stirrer for $30 \mathrm{~min}$. Once the gelatine was fully dissolved, $\beta$-TCP powder (33.5 $\mathrm{wt} \%, 31.5 \mathrm{wt} \%$ and $29.4 \mathrm{wt} \%$ ) and $0.25 \mathrm{wt} \%$ of polyvinyl alcohol (PVA) that acted as binder were slowly added into the gelatine solution to avoid bubble and coagulation. The mixture was stirred using mechanical stirrer at $300 \mathrm{rpm}$ until a homogenous mixture was obtained. The mixture was placed inside the vacuum desiccator for 2 min to reduce the formation of air bubble and then stirred again while adding $0.25 \mathrm{wt} \%$ glutaraldehyde (GA). Once a homogenous mixture was obtained, the slurries were poured into PVC pipe and allowed to freeze in a freezer (PhiTec International, United Kingdom) for $24 \mathrm{~h}$ at freezing temperature of $-10^{\circ} \mathrm{C}$. The frozen slurries were then placed inside the freeze dryer to be freeze dried for $24 \mathrm{~h}$ at pressure of $0.5 \mathrm{bar}$.

\subsection{Preparation of Biphasic $\alpha$-TCP/ $\beta$-TCP Scaffold}

After freeze drying process, the porous $\beta$-TCP scaffolds were sintered inside an elevated hearth furnace (EHF 1800, Lenton, United Kingdom). The sintering was divided into two stages. The first stage was carried out to burn off the gelatine. This was done at $500^{\circ} \mathrm{C}$ for $1 \mathrm{~h}$ at heating rate of $5^{\circ} \mathrm{C} \mathrm{min}^{-1}$. Once the first stage was done, the second stage of sintering followed where the temperature was increased to $1300^{\circ} \mathrm{C}$ with different soaking times of $2 \mathrm{~h}, 4 \mathrm{~h}$ and $6 \mathrm{~h}$ and then immediately quenched in air to partially transform the $\beta$-TCP phase into $\alpha$-TCP phase. Similar steps were done for temperature $1300^{\circ} \mathrm{C}$. For phase analysis, X-Ray diffraction (XRD) analysis was done (XRD, D8 Advance Bruker-binary V3, Bruker, United States) and Fourier transformed infrared spectroscopy (FTIR, Perkin Elmer, MA, United States).

\subsection{Preparation of Biphasic $\beta-\mathrm{TCP} / \mathrm{CO}_{3} \mathrm{Ap}$ Scaffold}

The partially transformed $\beta$-TCP $/ \alpha$-TCP scaffolds were then immersed into $30 \mathrm{ml}$ of $1 \mathrm{M}$ of sodium bicarbonate $\left(\mathrm{NaHCO}_{3}\right)$ solution in a hydrothermal vessel for dissolution-precipitation reaction via hydrothermal. The hydrothermal vessel was then place in an oven (UN 160, Memmert. Germany) at $200^{\circ} \mathrm{C}$ for 5 days. After 5 days, the sample is removed from the hydrothermal vessel and washed thoroughly to remove excess $\mathrm{NaHCO}_{3}$. The sample is then dried overnight in room temperature prior for analysis. The microstructure of the specimen was observed using field emission scanning electron microscope (FESEM Supra 35VP Zeiss) while phase analysis was done using XRD and FTIR. 


\section{RESULTS AND DISCUSSION}

\subsection{Phase Transformation of $\beta$-TCP Scaffold after Sintering}

Figure 1 shows the XRD patterns of the samples sintered at $1300^{\circ} \mathrm{C}$. It can be observed that all the peaks matched to both commercial $\alpha$ - and $\beta$-TCP phase and similar results can be observed for samples sintered at $1300^{\circ} \mathrm{C}$ for $2 \mathrm{~h}, 4 \mathrm{~h}$ and $6 \mathrm{~h}$. A slight shift in the peaks was due to the formation of biphasic $\alpha-\mathrm{TCP} /$ $\beta$-TCP phase whereby the "loose" structure of $\alpha$-TCP causes lattice strain and broaden the peaks. ${ }^{9}$ Figure 2 shows the percentage of $\alpha$-TCP phase transformed for samples sintered at $1300^{\circ} \mathrm{C}$. For samples soaked for $2 \mathrm{~h}$ and $4 \mathrm{~h}$, the decrease in the percentage of $\alpha$-TCP phase formed is insignificant regardless of the amount of gelatine used. However, for $6 \mathrm{~h}$ soaking time, it can be seen clearly that a decrease in the amount of $\alpha$-TCP phase formed as higher gelatine content was used. This is because as the gelatine content increases, the amount of $\beta$-TCP powder used decreases during the fabrication of the scaffolds. Thus, less $\beta$-TCP is available to be transformed to $\alpha$-TCP. Higher amount of $\alpha$-TCP phase was formed as the soaking time was prolonged to $6 \mathrm{~h}$. However, regardless of the amount of gelatine used, the amount of phase transformation to $\alpha$-TCP was insignificant in comparison to the same soaking time.

\subsection{Phase Transformation of Biphasic $\beta$-TCP/ $\alpha$-TCP Scaffold to Biphasic $\beta-\mathrm{TCP} / \mathrm{CO}_{3}$ Ap Scaffold}

Figure 3 shows the XRD of commercial $\beta$-TCP, commercial $\alpha$-TCP, $\beta$ - $\alpha$-TCP with $1 \mathrm{wt} \%, 3 \mathrm{wt} \%$ and $5 \mathrm{wt} \%$ of gelatine sintered at $1300^{\circ} \mathrm{C}$ for $2 \mathrm{~h}, 4 \mathrm{~h}$ and $6 \mathrm{~h}$ with commercial HAp. All samples show apatite peaks that matched the commercial HAp with some traces of $\beta$-TCP. Longer soaking time produced more apatite peaks in the samples as shown in Figure 4. It can be observed that regardless of soaking time, the formation of apatite phase decreases as the gelatine content increases. As mention earlier, the higher amount of gelatine used in the fabrication process reduced the amount of $\beta$-TCP powder used, and therefore the amount of $\alpha$-TCP phases also reduced. This $\alpha$-TCP phase is then expected to transform into $\mathrm{CO}_{3} \mathrm{Ap}$ by dissolution-precipitation reaction. ${ }^{9}$ Figure 5 illustrates the FTIR spectra of biphasic $\beta-\mathrm{TCP} / \mathrm{CO}_{3} \mathrm{Ap}$ scaffolds sintered at $1300^{\circ} \mathrm{C}$ for $6 \mathrm{~h}$. Bands can be observed bands in the range of $3693-3573 \mathrm{~cm}^{-1}$ that belongs to the $\mathrm{v}_{\mathrm{s}}$ mode of hydroxyl group while in range $1469-1409 \mathrm{~cm}^{-1}$ and peak at $873 \mathrm{~cm}^{-1}$ shows the v3 mode of the $\mathrm{C}-\mathrm{O}$ bond of carbonate ion. The presence of this peak shows that the sample contained $\mathrm{CO}_{3}{ }^{2}$, thus confirming that carbonate apatite was indeed obtained from the hydrothermal reaction. ${ }^{10}$ A-type carbonate apatite shows IR absorption near $879 \mathrm{~cm}^{-1}$, while B-type is at $871 \mathrm{~cm}^{-1} .{ }^{11}$ Since there are presence of C-O 
(a)

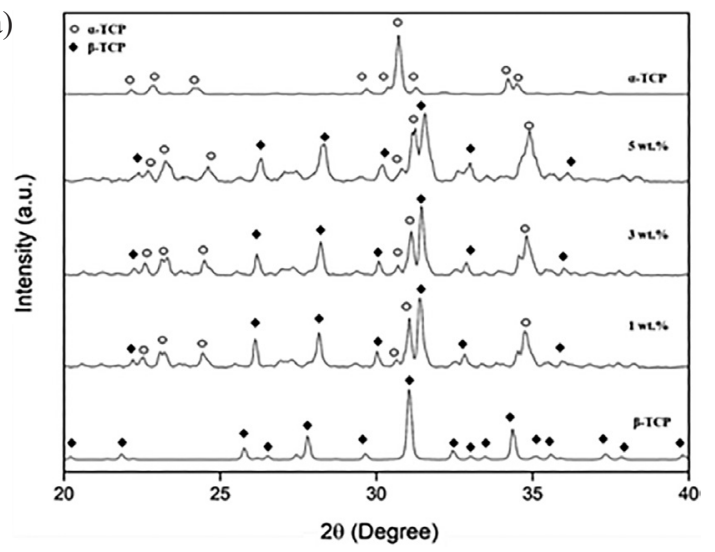

(b)

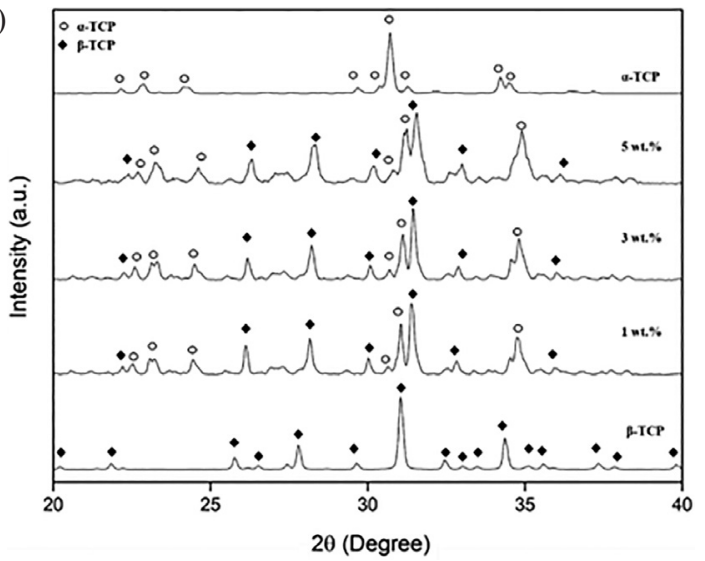

(c)

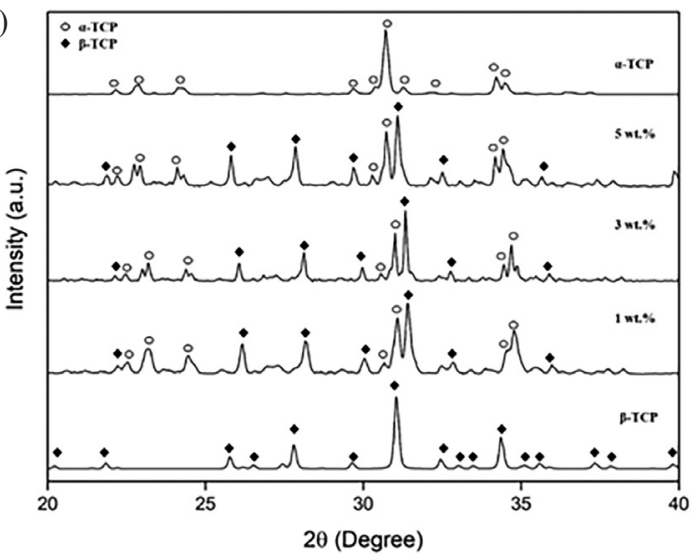

Figure 1: XRD pattern of commercial $\beta$-TCP, $\beta$-TCP scaffold with $1 \mathrm{wt} \%, 3 \mathrm{wt} \%$ and $5 \mathrm{wt} \%$ of gelatine sintered at $1300^{\circ} \mathrm{C}$ for (a) $2 \mathrm{~h}$, (b) $4 \mathrm{~h}$ and (c) $6 \mathrm{~h}$. 
band at $\sim 873 \mathrm{~cm}^{-1}$ for all samples, it can be assumed that the samples obtained is of B-type carbonate. However, it can be seen in Figure 5 the presence of weak hydroxyl stretch band at about $3693-3573 \mathrm{~cm}^{-1}$ which can indicates the presence of A-type carbonate. Thus, it can be concluded that not only B-type carbonate is present but also A-type coexist in the obtained $\mathrm{CO}_{3} \mathrm{Ap}$, which is in agreement with the results reported by Tsuru et al. ${ }^{12}$

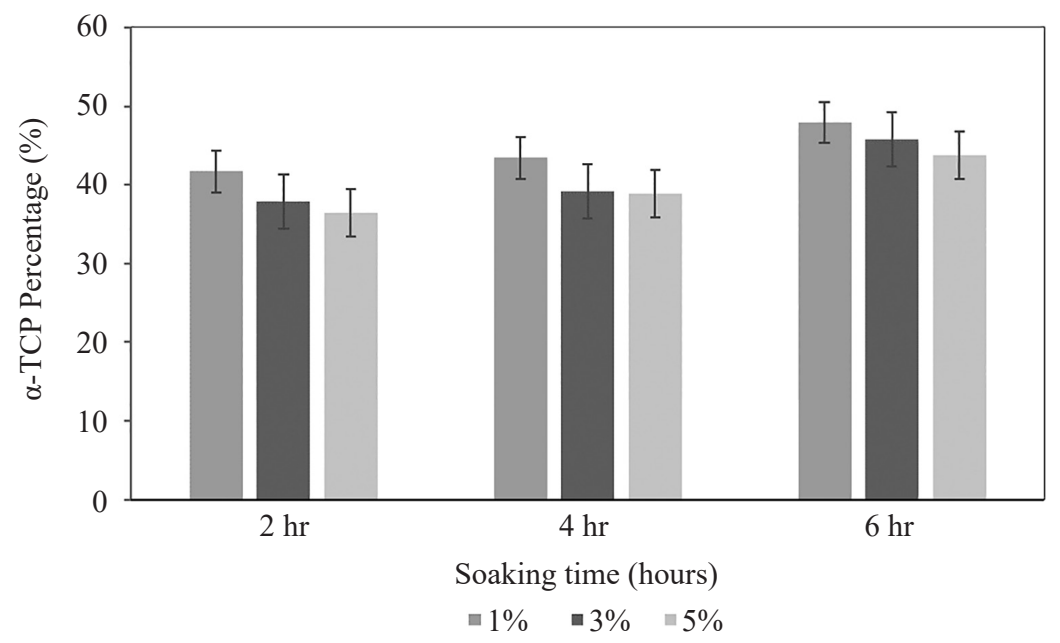

Figure 2: Percentage of $\alpha$-TCP phase in $\beta$-TCP scaffold sintered at $1300^{\circ} \mathrm{C}$ f for $2 \mathrm{~h}, 4 \mathrm{~h}$ and $6 \mathrm{~h}$ with $1 \mathrm{wt} \%, 3 \mathrm{wt} \%$ and $5 \mathrm{wt} \%$ of gelatine.

\subsection{Morphological Analysis of Biphasic $\beta-\mathrm{TCP} / \mathrm{CO}_{3} \mathrm{Ap}$ Scaffold}

The morphology of the scaffold was examined by FESEM. The effect of $\beta$-TCP/ gelatine ratio and sintering time on the morphology of the $\beta-\mathrm{TCP} / \mathrm{CO}_{3} \mathrm{Ap}$ scaffold are shown in Table 1. For all samples sintered for $2 \mathrm{~h}$, a needle-like structure that is typical for carbonated apatite can be observed which indicates that carbonate apatite is successfully formed from the dissolution-precipitation process. ${ }^{13}$ Sample that contained $1 \mathrm{wt} \%$ gelatine sintered for $2 \mathrm{~h}$ showed small equiaxed crystal formed together with needle-like structure, indicating that there are some $\beta-/ \alpha$ TCP not yet transformed into carbonate apatite. The needle-like structure can be observed for samples with $3 \mathrm{wt} \%$ and $5 \mathrm{wt} \%$ of gelatine sintered for $4 \mathrm{~h}$. However, samples with $1 \mathrm{wt} \%$ gelatine show small plate-like crystal. Typically, plate-like crystals are associated with $\beta$-TCP that have low solubility will form crystals aligned to each other to form crystal structure. ${ }^{14}$ However, in this case, the reasons for the formation of plate-like crystal is unknown. All samples sintered for $6 \mathrm{~h}$ shows equiaxed crystal. The equiaxed crystal formed may be due to the longer soaking time during sintering. 
(a)

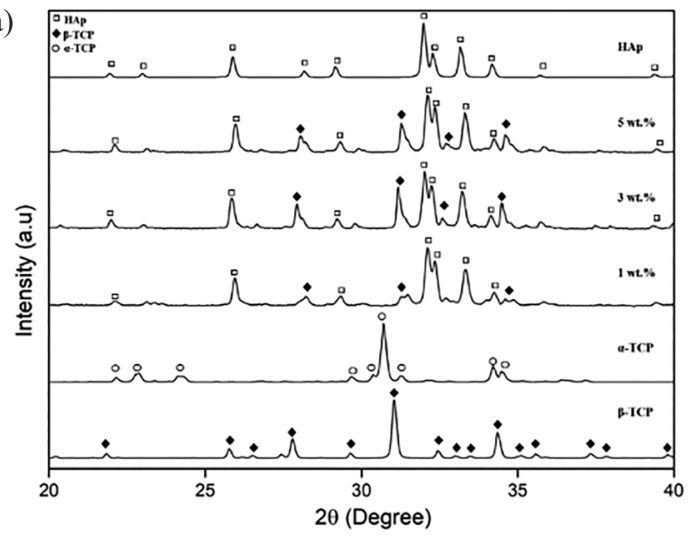

(b)

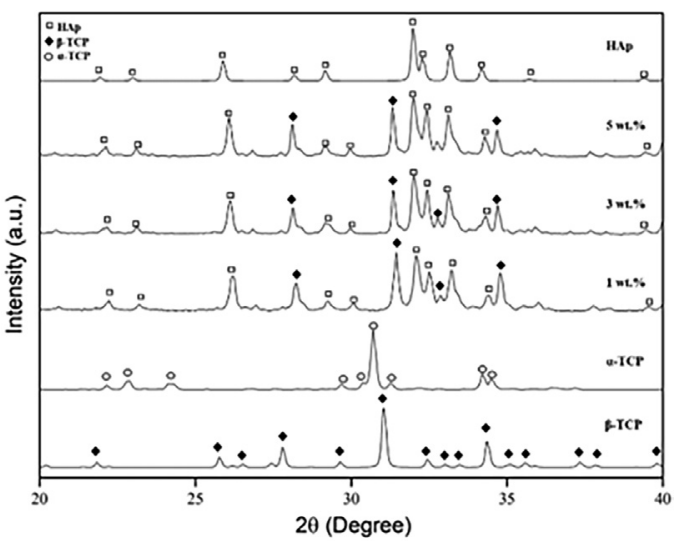

(c)

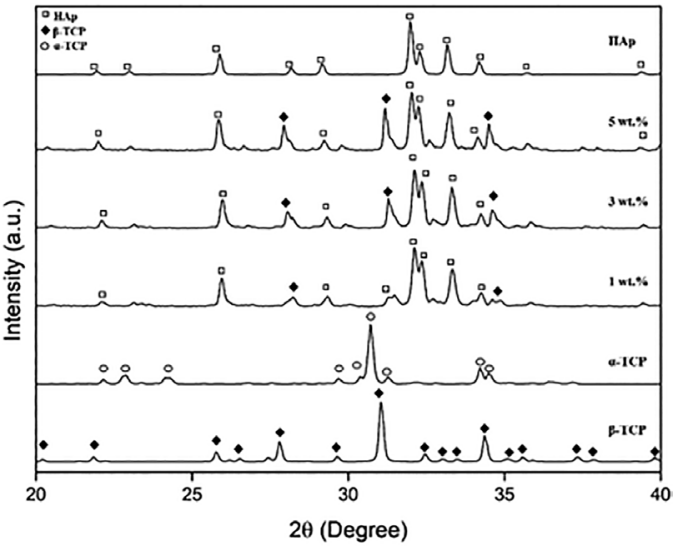

Figure 3: XRD pattern of commercial $\beta$-TCP, $\beta$-TCP scaffold with $1 \mathrm{wt} \%, 3 \mathrm{wt} \%$ and $5 \mathrm{wt} \%$ of gelatine sintered at $1300^{\circ} \mathrm{C}$ for (a) 2 , (b) $4 \mathrm{~h}$ and (c) $6 \mathrm{~h}$, after hydrothermal treatment. 


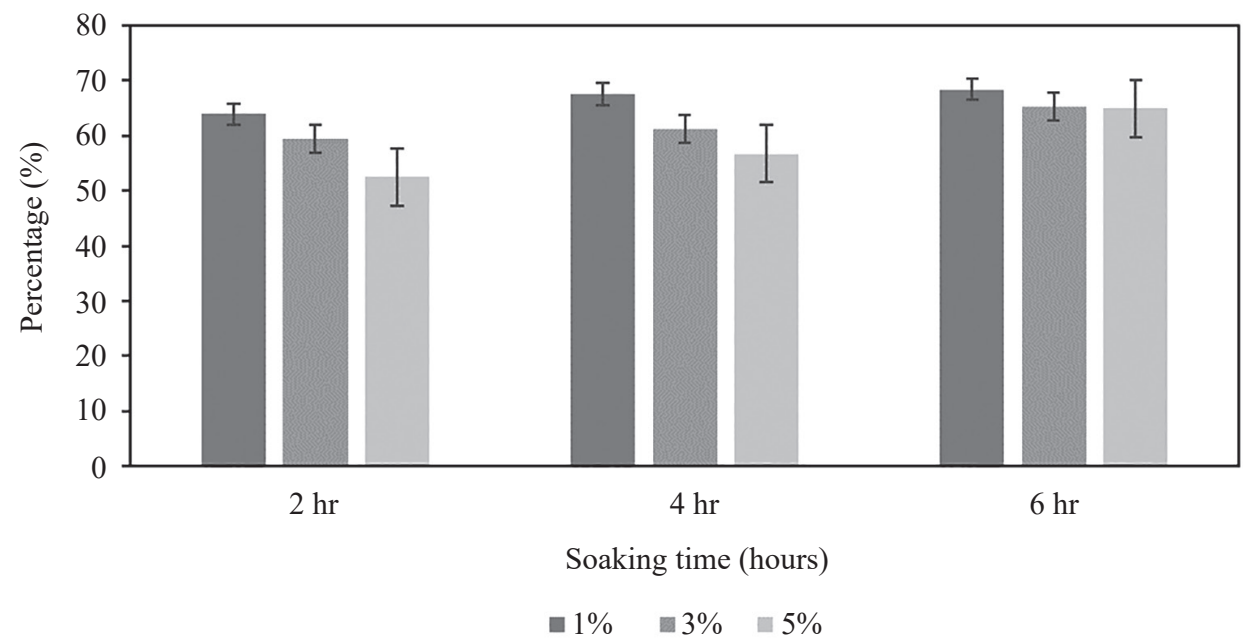

Figure 4: Percentage of apatite peaks in samples sintered at $1300^{\circ} \mathrm{C}$ for $2 \mathrm{~h}, 4 \mathrm{~h}$ and $6 \mathrm{~h}$ with $1 \mathrm{wt} \%, 3 \mathrm{wt} \%$ and $5 \mathrm{wt} \%$ of gelatine, after hydrothermal treatment.

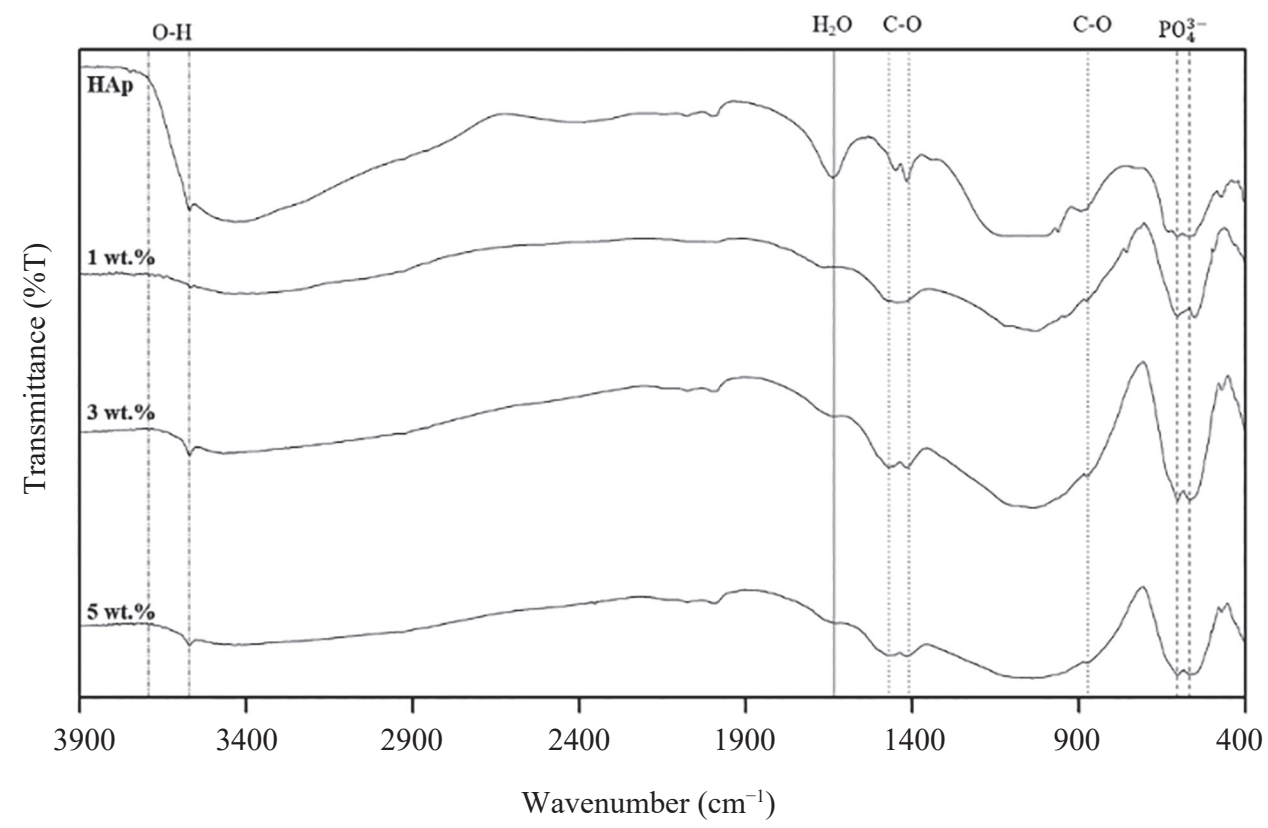

Figure 5: FTIR spectra of biphasic $\beta$-TCP/ with $1 \mathrm{wt} \%, 3 \mathrm{wt} \%$ and $5 \mathrm{wt} \%$ of gelatine, after hydrothermal treatment. 
Table 1: Morphology of biphasic $\beta-\mathrm{TCP} / \mathrm{CO}_{3} \mathrm{Ap}$ scaffold at $1 \mathrm{wt} \%, 3 \mathrm{wt} \%$ and $5 \mathrm{wt} \%$ of gelatine and sintered with soaking time duration of $2 \mathrm{~h}, 4 \mathrm{~h}$ and $6 \mathrm{~h}$.

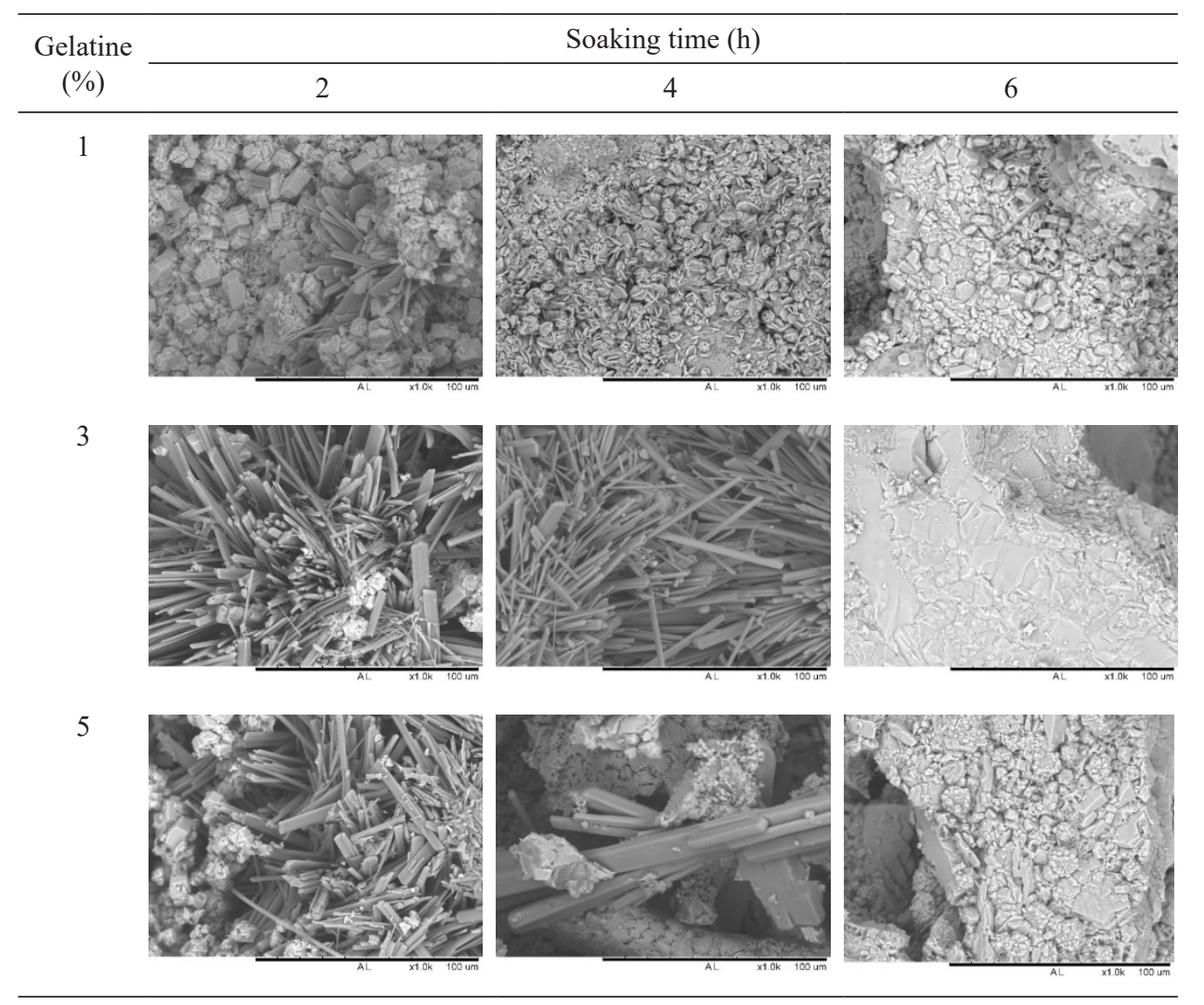

\section{CONCLUSION}

As a conclusion, biphasic $\beta-\mathrm{TCP} / \mathrm{CO}_{3} \mathrm{Ap}$ scaffolds was successfully fabricated through freeze drying method followed by dissolution-precipitation reaction in hydrothermal process with three different gelatine composition $(1 \mathrm{wt} \%, 3 \mathrm{wt} \%$ and $5 \mathrm{wt} \%)$ at sintering temperature of $1300^{\circ} \mathrm{C}$ for three soaking times $(2 \mathrm{~h}, 4 \mathrm{~h}$ and $6 \mathrm{~h})$. Increase in gelatine content will decreases the percent of phase transformation. However, longer soaking time increases the number of phase transformation from $\beta$-TCP to $\alpha$-TCP. This leads to an increase in $\mathrm{CO}_{3} \mathrm{Ap}$ formation after dissolutionprecipitation reaction as the amount of unstable phase $(\alpha-\mathrm{TCP})$ increases with longer soaking time. 


\section{ACKNOWLEDGEMENTS}

This work is financially supported by Universiti Sains Malaysia Bridging Grant (grant no. 304.PBAHAN.6316318).

\section{REFERENCES}

1. Tang, X. et al. (2016). Fabrication, characterization and cellular biocompatibility of porous biphasic calcium phosphate bioceramic scaffolds with different pore sizes. Ceram. Int., 42(14), 15311-15318, https://doi.org/10.1016/j.ceramint.2016.06.172.

2. Doi, Y. et al. (1999). Osteoclastic responses to various calcium phophates in cell cultures. J. Biomed. Mater. Res., 47, 424-433.

3. Okuda, T. et al. (2007). The effect of the microstructure of $\beta$-tricalcium phosphate on the metabolism of subsequently formed bone tissue. Biomat., 28, 2612-2621, https://doi.org/10.1016/j.biomaterials.2007.01.040.

4. Zhang, D. et al. (2018). The development of collagen based composite scaffolds for bone regeneration. Bioact. Mater., 3(1), 129-138, https://doi.org/10.1016/j. bioactmat.2017.08.004.

5. Dwi Ariani, M. et al. (2013). New development of carbonate apatite-chitosan scaffold based on lyophilization technique for bone tissue engineering. Dent. Mater. J., 32(2), 317-325 https://doi.org/10.4012/dmj.2012-257.

6. Hasegawa, M., Doi, Y. \& Uchida, A. (2003). Cell-mediated bioresorption of sintered carbonate apatite in rabbits. J. Bone Joint Surg., 85, 142-147, https://doi. org/10.1302/0301-620X.85B1.13414.

7. Wakae, H. et al. (2008). Fabrication of macroporous carbonate apatite foam by hydrothermal conversioan of alpha tricalcium phosphate in carbonate solutions. J. Biomed. Mater. Res. A, 87(4), 957-963, https://doi.org/10.1002/jbm.a.31620.

8. Maruta, M. et al. (2011). Fabrication of low-crystalline carbonate apatite foam bone replacement based on phase transformation of calcite foam. Dent. Mater. J., 30(1), 14-20, https://doi.org/10.4012/dmj.2010-087.

9. Yong, X. H., Mazlam, M. I. \& Ahmad, N. (2018). Fabrication and characterization of porous biphasic $\beta$-tricalcium phosphate/ carbonate apatite alginate coated scaffolds. Cer. Inter., 44, 9499-9505, https://doi.org/10.1016/j.ceramint.2018.02.168.

10. Chaudhry, A. A. etal.(2012). Rapid hydrothermal flow synthesis and characterisation of carbonate- and silicate- substituted calcium phosphates. J. Biomat. App., 28(3), 448-461, https://doi.org/10.1177\%2F0885328212460289.

11. Kourkoumelis, N. \& Tzaphlidou, M. (2010). Spectroscopic assessment of normal cortical bone: Differences in relation to bone site and sex. Sci. World J., 10, 402412, https://doi.org/10.1100/tsw.2010.43. 
12. Tsuru, K. et al. (2017). Fabrication of carbonate apatite block through dissolutionprecipitation reaction using calcium hydrogen phosphate dihydrate block as a precursor. Mater., 10(4), 374, https://dx.doi.org/10.3390\%2Fma10040374.

13. Mamat, N. Mustapha, M. \& Abdul Hamid, Z. A. (2017). Fabrication of carbonate apatite based on hydrothermal reaction using freeze-casted $\beta$-TCP precursor. Solid State Phenom., 264, 50-53, https://doi.org/10.4028/www.scientific.net/ SSP.264.50. 